\title{
O Mito da Mãe Exclusiva e seu Impacto na Depressão Pós-Parto
}

\author{
The Myth of the Exclusive Mother and its Impact on Postnatal Depression
}

\author{
Kátia Rosa Azevedo* \& Alessandra da Rocha Arrais \\ Universidade Católica de Brasília, Brasília, Brasil
}

\begin{abstract}
Resumo
Este artigo é resultado de um estudo qualitativo, baseado na Epistemologia Qualitativa, que visou promover reflexões acerca da depressão pós-parto, enfatizando os fatores psicossociais envolvidos. Trata-se de um estudo de caso sobre uma das participantes do grupo de apoio e orientação a mães com depressão pós-parto, desenvolvido na Universidade Católica de Brasília. Este grupo visou proporcionar um espaço de escuta emocional e apoio às puérperas, e foi campo para coleta de dados. Utilizou-se da técnica de completamento de frases, de técnicas projetivas, e de relatos apresentados nas sessões individuais e grupais para levantamento e construção de indicadores sobre a vivência da maternagem e da depressão pós-parto. O estudo deste caso forneceu-nos elementos para compreendermos o quão prejudicial pode ser o ideal de maternidade apresentado como natural e instintivo para mulheres que buscam satisfação absoluta na maternidade, configurando-se como um dos responsáveis pela instalação e manutenção da depressão pós-parto.

Palavras-chave: Depressão pós-parto; maternidade; ambivalência.
\end{abstract}

\begin{abstract}
This article is the result of a qualitative study, based on Qualitative Epistemology, aimed to promote reflections on postnatal depression, emphasizing the psychological and social factors involved. This is a case study about one of the participants of a support group for mothers with postnatal depression, developed at the Universidade Católica de Brasília. The aim of this group was to provide a space of emotional listening and support, and it was a field for collecting data. The technique of completing phrases, projective techniques, and accounts presented in individual and group sessions were used for the survey and construction of indicators about the experience of maternity and postnatal depression. The study of this case gave us elements to understand how an ideal of maternity presented as natural and instinctive can be harmful for women that try to obtain absolute satisfaction in their experience of maternity, configuring this ideal as one of the responsible elements for the installation and maintenance of postnatal depression.

Keywords: Postnatal depression; maternity; ambivalence.
\end{abstract}

O que teria a depressão a ver com a festa que cerca o nascimento de um bebê? Como entender que este momento considerado normal e tão comum ao ciclo vital de qualquer ser humano se transforme em um momento depressivo, quando a mãe sente-se angustiada, insegura, sensível demais, entristecida e chorando desesperadamente?

No ciclo vital da mulher há três períodos críticos: a adolescência, a gravidez e o climatério, são períodos de transição que constituem fases do desenvolvimento da personalidade e que possuem vários pontos em comum (Diniz, 1999). São fases biologicamente determinadas, caracterizadas por mudanças metabólicas e hormonais complexas; por reajustamentos interpessoais e intrapsíquicos, mas também por alterações interpessoais e interpsíquicas. Tantas mudanças podem resultar em estados temporários de desequilíbrio, e em significativas alterações na identidade da mulher devido às grandes expectativas quanto ao papel social esperado (Maldonado, Dickstein, \& Nahoum, 2000).

Entendemos que desde a infância as meninas treinam o papel de boa mãe, segundo o qual a mulher deve ser capaz

"Endereço para correspondência: Centro Clínico do Guará, OE 01 - Área Especial F, sala 208, Guara I, Brasília - DF CEP 71020-061.E-mail: kati.rosa@yahoo.com.br de enormes sacrifícios, entre eles ser amável, tranqüila, compreensiva, terna, equilibrada, acolhedora, feminina em tempo integral! Espera-se um ideal, um modelo de mãe perfeita, uma imagem romanceada da maternidade construída ao longo dos últimos séculos, que está alicerçada sob um rígido padrão incapaz de admitir qualquer vestígio de sentimentos ambivalentes nas mães.

Acontece, porém, que na ocasião do nascimento de um filho, a maioria das mulheres experimentam sentimentos contraditórios e inconciliáveis com a imagem idealizada de maternidade ditada pela cultura. Desta forma, estabelece-se um conflito entre o ideal e o vivido e instaura-se um sofrimento psíquico que pode se configurar como uma base para a depressão após o parto.

\section{A Natureza Feminina: O Mito da Mãe Perfeita}

De maneira geral, as crenças sobre a maternidade são divulgadas como se fossem tradicionais e naturais, e por serem concebidas assim, essas crenças se tornam inatacáveis. Contudo, é possível verificar na história da humanidade que essas idéias têm poucas centenas de anos. A boa mãe, tal qual conhecemos hoje, com sua propensão natural ao sacrifício, seu amor universal e automático pelos filhos e sua completa satisfação nas tarefas da maternidade, não foi sempre assim. 
Ao contrário disso, Forna (1999) nos conta que esse estilo de maternagem teve seu início em 1762, a partir da publicação de Émile, por Rousseau, quando este criticou as mães que enviavam os filhos para as amas-de-leite, o que era bastante comum até esta época. Ele recomendava, enfaticamente, que as próprias mães amamentassem e criassem seus filhos e as recriminava por darem preferência a outros interesses. Segundo Badinter (1985) dá-se aí, o início à injunção obrigatória do amor materno. Serrurier (1993) também afirma que é deste Émile, que estamos condenadas a ser mães e a ser boas mães. Não há alternativa para a mulher: a vocação materna é natural, instintiva e obrigatória!

Contrária às idéias de que a maternidade só comporta o amor irrestrito e apoiando a perspectiva das teorias do gênero, segundo a qual a maternidade é construída e não instintiva, a maternidade e a maternagem, segundo os antropólogos e sociólogos, é um constructo social e cultural que decide não só como criar os filhos, mas também, quem é responsável por eles (Forna, 1999).

Culturalmente, as representações sociais da maternidade estão fortemente calcadas no mito de mãe perfeita. Esta concepção assume proporções insustentáveis, segundo as quais acredita-se que a maternidade é inata à mulher. É a idéia de que a maternidade é parte inerente ao ciclo evolutivo vital feminino. Neste sentido, supõe-se que a mulher, por ser quem gera os filhos, desenvolve um amor inato pelas crianças e fica sendo a pessoa melhor capacitada para cuidar delas (Falcke \& Wagner, 2000).

Concluímos, portanto, que, apesar do crescente questionamento sobre o amor materno incondicional e inato, a visão da mãe ideal, responsável pelo bem-estar psicológico e emocional da família, ainda é bastante presente na literatura e no senso comum (Badinter, 1985). Acreditamos que esta insistência em que um certo estilo de maternidade é "natural", entra em choque com a vivência da maternagem, o que leva ao sentimento de "mãe desnaturada” e há muito sofrimento. Mas também, tem levado muitas mulheres, na atualidade, a questionarem cada aspecto do que fazem, pensam, sentem, e a avaliar suas próprias experiências, buscando flexibilizar o padrão rígido e determinista cultuado socialmente.

\section{A Mãe Moderna: Nova História, Velhas Representações}

Não há dúvidas que a inserção da mulher no mercado de trabalho tem trazido muitas transformações nas relações conjugais, que contribuíram para o declínio do sistema patriarcal e da hegemonia masculina, que pode ser observada, por exemplo, em um gradativo aumento do envolvimento masculino nos trabalhos domésticos. Todavia, dados atuais têm mostrado o descompasso entre os dois fenômenos, apontando crescimento acelerado de mulheres no mercado de trabalho, enquanto a participação masculina nos trabalhos domésticos vem crescendo lenta e gradualmente. Portanto, na família moderna ainda que o pai esteja mais presente em casa, a mãe continua sendo o maior parâmetro para os filhos pequenos. É ela quem continua com a maior parte das responsabilidades junto a casa e aos filhos, quem controla e cria os filhos e quem lhes dá uma imagem do mundo.

Assim, entendemos que há uma nova mulher, mas que vive sob o manto das velhas representações, pois continuamos cobrando delas o velho modelo de mãe idealizada. O problema, porém, é que as mulheres de hoje, já não são preparadas, não sabem e nem querem cuidar dos seus filhos como suas mães faziam. Elas têm outros interesses, desejos, informações, expectativas e, sobretudo outras alternativas para se realizarem como mulher, que não estão mais restritas à maternidade. Novamente, observase um conflito na vivência do papel moderno de mãe, que acarreta mais dúvidas, angústias e, sobretudo em culpa, que se revelam através da (des)conhecida ambivalência materna.

Parker (1997) nos diz que a ambivalência materna é a experiência compartilhada de forma geral por todas as mães, na qual coexistem lado a lado, em relação ao filho, sentimentos de amor e de ódio. Para esta autora, a dificuldade em enfrentar tais sentimentos tão complexos e contraditórios próprios da ambivalência materna pode redundar em uma eterna culpa, que implica em muito sofrimento, mas com a qual as mães se habituam a viver. Atualmente, culpa e maternidade são quase sinônimos.

Todas estas considerações nos levaram a acreditar que a maternidade como vem sendo concebida até nossos dias, tem influência direta no aparecimento da depressão no pósparto. Nossa hipótese é de que essas pressões culturais sob as quais as mulheres invariavelmente exercem a maternidade, associadas ao sentimento de incapacidade em adequar-se a uma visão romanceada desse estado, acabam por deixá-las ansiosas e culpadas, suscitando dessa maneira conflitos que predisporiam a depressão pós-parto.

Acreditamos que a mulher com depressão pós-parto estaria apenas expressando seu choque e desapontamento em não sentir toda a emoção e felicidade, normalmente mostrada nos filmes, nos livros, na igreja, nas brincadeiras de infância, nas propagandas de fraldas e de aleitamento materno e nas histórias das suas vizinhas e amigas. Por esta razão, entendemos que temas como a feminilidade, as transformações culturais no papel da mulher, o mito de mãe perfeita e a ambivalência do papel de mãe, guardam estreita relação com o que chamaremos possíveis causas da depressão após o parto.

\section{A Construção do Método}

Faz-se importante, antes de mencionarmos as bases em que foi pensado e construído este trabalho, ressaltarmos o embate metodológico pelo qual as ciências humanas e sociais têm passado nas últimas décadas. É uma batalha entre paradigmas, por um lado o paradigma hegemônico empírico/positivista e do outro, alternativo a este, o que se convencionou chamar de paradigma subjetivista/construtivista/interpretativo (Brito \& Leonardos, 2001).

Na prática, este embate é apresentado pelas pesquisas que seguem o método quantitativo, representando o primeiro paradigma e as pesquisas que adotam o método 
qualitativo, representando o segundo paradigma. Ao longo das últimas décadas, ambos métodos foram julgados, comparados e criticados e chegou-se a conclusão de que os dois têm seus aspectos favoráveis e desfavoráveis dependendo da investigação que se quer realizar.

No entanto, em função das peculiaridades do objeto de estudo da psicologia - a subjetividade humana - acreditamos que o método qualitativo é mais adequado ao seu estudo, pois os afetos como angústia, tristeza, desamparo, alegria, esperança, entre outros, fazem parte de uma gama de tonalidades diferentes de sentimentos, com os quais as pessoas vão experenciar e significar o seu ambiente físico, emocional, social, histórico e cultural, que não são passíveis de serem mensurados conforme os crivo positivistacartesiano. Assim, podemos afirmar que, nas últimas décadas observa-se um grande esforço na área da psicologia para produzir formas de conhecimento alternativas ao empirismo.

Um dos expoentes desta forma alternativa ao paradigma positivista de fazer ciência é representado por González Rey através da sua construção teórica denominada de Epistemologia Qualitativa (González Rey, 1997, 1999, 2001, 2002). González Rey se inscreve neste esforço de diferentes psicólogos, tanto no Brasil quanto no exterior, pois questiona as formas tradicionais de produção do conhecimento em psicologia, ainda predominantes no âmbito das pesquisas acadêmicas.

González Rey enfatiza a necessidade epistemológica de haver novas formas de produção de conhecimento perante um novo desafio nesta área. Para ele a pesquisa em psicologia exige uma compreensão de processos que não são acessíveis à experiência objetiva, o que implica considerar o fenômeno em toda a sua complexidade de inter-relações. Ele ressalta a importância do resgate da subjetividade, o que pressupõe uma evolução nas pesquisas em psicologia, implicando o reconhecimento da essência única do ser humano e da importância da apreensão desta realidade subjetiva no processo de construção e desenvolvimento de idéias, elementos imprescindíveis para o progresso da ciência.

\section{A Escolha Metodológica}

São por estas concepções que optamos pela Epistemologia Qualitativa, como constructo metodológico da nossa investigação, pois, os princípios desenvolvidos por esta metodologia favorecem o acesso ao sistema de sentidos elaborados pelas participantes, sendo este o objetivo central desta pesquisa: possibilitar a compreensão da produção de sentido das mães diante das experiências evocadas pela depressão pós-parto.

Os principais elementos do referencial Epistemológico qualitativo são, de acordo com González Rey (1997): o conhecimento é construído num processo construtivointerpretativo; o pesquisador também é "sujeito" deste processo, participa dele ativamente; o conhecimento não é resultado apenas de uma coleta de dados, é constituído a partir de um processo sócio-histórico-cultural, acessado através de recursos instrumentais alternativos.
As constatações empíricas cedem lugar a uma construção de sentidos na qual pesquisador e pesquisado desempenham papéis ativos. O pesquisador enfatiza os vários indicadores obtidos como elementos interligados e significativos, passíveis de interpretação subjetiva. Trabalhase com todas as formas de expressão do sujeito, com metáforas, expressões de diferentes tipos, e representações. Segundo González Rey (1999) o indicador se refere a aqueles elementos que adquirem significação graças à interpretação do pesquisador e só tem valor dentro dos limites do processo. Ele representa um momento hipotético no momento de produção da informação, se constrói a partir das informações que vão sendo geradas da inter-relação do pesquisador com o participante da pesquisa. Está sempre associado a um momento interpretativo.

Por isto, o instrumento a ser utilizado, tem sentido, na medida que se relaciona especificamente com o sujeito estudado. O objetivo não é criar categorias como nos testes de personalidade, mas sim preservar a singularidade dos sujeitos pesquisados e abrir novas zonas de sentido. Os instrumentos não devem oferecer restrições à participação espontânea dos indivíduos. É o meio utilizado para a produção dos indicadores que por sua vez ganharão sentido dentro do marco teórico e das reflexões do pesquisador.

O momento empírico, portanto, não representa apenas a coleta de dados, significa uma etapa de produção da informação, onde as idéias, os conceitos do pesquisador, o contexto histórico-socio-cultural constituem fases do processo de produção da informação. Por isso que se trabalha com indicadores e não com "dados", os dados existem, se consideram, se integram ao processo, mas não são considerados como fontes definitivas das conclusões. Já os indicadores permitem essa possibilidade de ter um processo ativo em constante movimento.

Assim, dentro dessa abordagem metodológica, o problema não aparece como entidade estática, mas como um momento de reflexão do pesquisador, no sentido de levantar questionamento sem pretensão de se chegar a respostas finais. Também, não há exigência de levantar hipóteses formais sobre o problema, pois não tem objetivo de provar ou verificar o fenômeno, mas de descrevê-lo da melhor maneira possível, no sentido de construir um conhecimento.

A Epistemologia Qualitativa favorece ainda, a consciência da impossibilidade de existência de uma causa única para qualquer fenômeno, o que nos possibilita realizar ricas reflexões sobre vivência da maternidade diante da depressão pós-parto.

\section{Objetivo geral}

Compreender os sentimentos e vivências pelos quais passam as puérperas que experimentam a depressão, valorizando/reconhecendo os fatores psicossociais envolvidos, tanto em suas repercussões na vida psíquica da mulher, quanto em sua vida relacional, sobretudo com seu bebê. 


\section{Objetivos específicos}

Compreender a vivência da maternidade apesar da depressão, procurando entender como os sintomas da depressão - fracasso, incapacidade, culpa, tristeza, irritabilidade - interagem na significação da maternidade e na configuração da subjetividade da mulher/mãe. Compreender o processo de significação e de elaboração subjetiva da maternidade, a partir da vivência da depressão pós-parto, em relação a si mesma e de seu estilo de maternagem. O estudo também tem a intenção de estimular o apoio psicológico precoce em maternidades e refinar a abordagem técnica do transtorno da depressão pós-parto.

\section{Métodos de Apreensão da Realidade}

Em consonância com a metodologia adotada, vários foram os recursos utilizados para acessarmos as vivências das mães que participaram do estudo, a saber:

\section{Técnica de completamento de frases}

Trata-se de uma técnica desenvolvida por González Rey (1997, 1999, 2001, 2002), a partir do teste clássico de associação de palavras de Jung. Consiste na apresentação de sessenta e sete frases escritas, incompletas, para que as participantes as completassem a partir daquilo que primeiramente emergisse em suas mentes ao ler a frase em questão. As frases incompletas suscitam questões relacionadas ao desejo, às preocupações, às aspirações, ao trabalho, às relações sociais, à maternidade, à depressão pós-parto, à amamentação, entre outros. O objetivo era auxiliar na produção dos indicadores.

\section{Escala de Depressão Pós-Parto de Edimburgo}

Foi aplicada esta escala para confirmação diagnóstica da depressão pós-parto. Ainda que tenhamos criticado os recursos metodológicos quantitativos-positivistas na seção anterior deste trabalho, reconhecemos que eles são válidos para auxiliar no diagnóstico e também podem ser analisados em termos do conteúdo abordados pelos mesmos. Assim, utilizamos esta escala, na intenção de selecionar as participantes para o grupo, e também para nos auxiliar na interpretação das configurações subjetivas das participantes, sobretudo com relação à presença de pensamentos suicidas. A Escala de Edimburgo consiste em um instrumento de auto-registro composto de dez enunciados, cujas opções são pontuadas (O a 3) de acordo com a presença ou intensidade do sintoma. Seus itens cobrem sintomas como: humor deprimido ou disfórico, distúrbio do sono, perda do prazer, idéias de morte e suicídio, diminuição do desempenho e culpa (Santos, Martins \& Pasquali, 1999; Santos, 1995).

\section{Entrevista de acolhimento e triagem}

$\mathrm{O}$ acolhimento psicológico visou oferecer uma escuta especializada às mães que chegaram ao nosso serviço, no sentido de ouvir, acolher e encaminhar adequadamente suas demandas e triá-las para o atendimento breve, individual e/ou em grupo.
Grupo de apoio e orientação às mães com depressão pós-parto

Aconteceu no Centro de Formação em Psicologia Aplicada - CEFPA, que é uma unidade do Curso de Psicologia da UCB. O grupo visou proporcionar às puérperas um espaço de escuta emocional e apoio onde o tema da depressão pós-parto pudesse ser adequadamente abordado, buscando fornecer não apenas informações cognitivas, mas, principalmente, permiti-las expressar livremente seus temores e ansiedades. No grupo elas receberam assistência e orientação psicológica para enfrentar as diversas situações de maneira mais adaptativa, realista e confiante. Foram abordados temas como: a vivência da DPP, o conceito da depressão pós-parto, o bebê imaginário X o bebê real, a transição para a maternidade, os novos vínculos, mãe-bebê, a tríade mãe-pai-bebê, fatos e mitos relacionados à maternidade, a importância da rede social de apoio, as alterações da vida do casal, a influência das avós, entre outros. Estes temas permitiram desdobrar a reflexão sobre a maternidade e as dificuldades enfrentadas pela mãe com o diagnóstico de depressão pós-parto, inclusive com análise de questões mitificadas e implícitas à maternidade.

O grupo tinha um caráter interativo, onde as mães eram convidadas a falar e a se colocarem quando quisessem. Era um grupo fechado, homogêneo quanto ao diagnóstico de depressão pós-parto, mas heterogêneo no que diz respeito à fase de pós-parto, idade da mãe, escolaridade, classe social, estado civil.

O grupo teve a duração de quatro meses, em sessões semanais, com duração média de 2 horas. Contou com 8 participantes. Cada um dos encontros tinha temas propostos pelas participantes; foram utilizadas técnicas de dinâmica de grupo, técnicas projetivas, filmes, aulas expositivas e debates.

\section{Atendimentos psicoterápicos individuais}

Paralelamente ao grupo, foram realizados atendimentos individuais, conforme a demanda das participantes, com o objetivo de potencializar a elaboração emocional realizada no grupo.

\section{Sujeito do estudo de caso}

A Sra. Vanuza, (os nomes serão fictícios para preservação da identidade dos envolvidos na pesquisa) sujeito do presente estudo, tem 37 anos, é natural de Goiânia e residente em Brasília, casada com Cláudio com quem tem uma filha de 10 meses, gerada por meio de fertilização artificial e trabalha como assistente social.

Vanuza procurou nosso serviço em novembro de 2002, queixando-se de depressão após o parto: muita tristeza, desânimo, cansaço, estresse, irritabilidade, pessimismo e oscilação do humor. Entretanto, durante os encontros em grupo, quando surgiam discussões a respeito do termo depressão pós-parto, Vanuza não se sentia confortável em aceitar para si tal diagnóstico.

Quanto ao relacionamento com os pais, Vanuza demonstra distanciamento do pai, e apresenta ter forte vínculo com sua mãe, sendo esta considerada sua verdadeira e única rede de apoio, sobretudo após o nascimento da filha. 
Atualmente, Vanuza não se refere a muitos amigos, e diz estar tendo dificuldades com colegas de trabalho. Seu envolvimento com grupos sociais parece ter diminuído após o nascimento da filha, pois se diz isolada, participando pouco de atividades sociais.

Sente muita dificuldade em cuidar da filha, tem muito medo de perdê-la e ao mesmo tempo sente vontade de sumir. É muito preocupada com a saúde da filha. Vanuza fala constantemente sobre problemas relacionados à dificuldade de dormir. Seu sono é, segundo ela, péssimo. Acorda várias vezes para dar o peito ou cuidar da filha. Vanuza apresenta apetite rebaixado, emagreceu $8 \mathrm{~kg}$ depois do parto e está abatida fisicamente. O relacionamento conjugal está muito ruim, questiona-se inclusive sobre uma possível separação, sobretudo por que sente-se desestimulada e pouco disponível para o ato sexual e esta tem sido uma das áreas de conflito atual com o marido.

\section{Resultados e Discussão}

Vanuza é uma mulher que escolheu ter filhos mais tarde, depois de cuidar da carreira profissional, passando a imagem de mulher dinâmica, auto-suficiente e ativa. Em contrapartida, desde a infância treina em sua família de origem o papel de boa mãe, segundo o qual a mulher deve ser capaz de enormes sacrifícios em tempo integral e sentir-se com isso plenamente realizada. Vanuza nos diz que sempre gostou muito de criança e por isso acreditava que seria uma boa mãe (com toda ambivalência que este termo pode suscitar em nossa cultura). Sua filha é fruto de uma longa e angustiante espera, um bebê muito desejado e amado desde a idéia de engravidar. Acontece que, segundo relatos da paciente, o nascimento de Carol a fez ficar muito nervosa, cansada, irritada, e ansiosa, levando-a a uma grande decepção e à depressão. Observa-se, neste caso, indicadores de conflito entre o esperado e o vivido, com reflexos no desempenho do papel materno.

$\mathrm{Na}$ técnica de completamento de frases utilizada, observamos vários indicadores deste conflito com a maternidade vivido por Vanuza: "Eu amo... minha filha; sempre quis... ter uma filha; minhas aspirações... ser boa mãe, e uma boa profissional; algumas vezes... tenho vontade de sumir; sofro... pois não sou a pessoa que desejava ser; o fracasso... está sempre presente; meu maior medo... perder a minh a filha; me esforço..._para ser uma boa mãe; as contradições... são constantes; para mim a maternidade... não foi o que sonhei; eu freqüentemente reflito...que estou muito deprimida".

O discurso apresentado por Vanuza durante as sessões de grupo, também denota sentimentos de fracasso e inadequação por ter comportamentos incompatíveis com a representação da maternidade que associa feminilidade a atitudes passivas. Desenvolvendo uma técnica projetiva de colagem, pedimos às mães que produzissem um cartaz com o que elas entendiam que era ser mãe e ser pai. Entre outros conteúdos, Vanuza comunicou que ser mãe é: "não ir ao shopping; ser mãe é não ter tempo para conversar com as amigas; ser mãe é não ter tempo para si mesma; o difícil é ser várias coisas e ser mãe quando se tem poucas pessoas para ajudar; ser mãe é dedicação exclusiva”. Vanuza faz uma breve lista de renúncias, de abnegação, quase uma punição, compatíveis com a postura socialmente esperada das boas mães, que devem padecer no paraíso e se sacrificar por sua prole.

A atitude passiva por si só não representa um indicador de conflito com a maternidade, mas se analisada juntamente com outros aspectos da configuração subjetiva revelada em Vanuza, podem indicar uma tendência masoquista comum às mães que se propõem a atender rigidamente aos critérios da mãe idealizada. Serrurier (1993) nos fala que uma das conseqüências dessa atitude passiva é o masoquismo materno. Sobre esse aspecto, Parker (1997) clarifica que é possível ver as estruturas masoquistas como uma tentativa de lidar com, e de se defender da culpa evocada pelo ódio materno. As mães podem empregar com os filhos maneiras excessivamente generosas, hiperaltruístas, numa tentativa de obter uma absolvição desses impulsos que as enchem de culpa. Nesse sentido, o masoquismo materno tem a ver com a ambivalência materna.

Esta ambivalência também aparece na Escala Edimburgo. Além de ter confirmado o diagnóstico de depressão pós-parto, o conteúdo de algumas respostas foram reveladores: "Eu tenho me culpado sem necessidade quando as coisas saem erradas: sim, na maioria das vezes", "A idéia de fazer mal a mim mesma passou por minha cabeça: Algumas vezes nos últimos dias". Essas respostas ilustram mais uma vez a culpa e a ambivalência sentidas por Vanuza.

Estes sentimentos ilustram bem o pensamento de Parker (1997) segundo o qual, amor e ódio são sensações experimentadas pela maior parte das mães. A culpa, segundo a autora, provocada por esses impulsos conflitantes, dificilmente é assumida e inconscientemente acaba por levá-las a dirigirem esta hostilidade para si próprias. É nesse sentido que as respostas de Vanuza à escala de Edimburgo confirmam uma estreita relação entre a ambivalência materna, sentimento de culpa e masoquismo materno.

Um outro aspecto bastante ressaltado por Vanuza, durante o grupo de apoio, diz respeito à sua rede de apoio social. Ela significa como agravante de sua insegurança e ansiedade quando dos cuidados com a filha o fato de sua mãe e família estarem morando em outra cidade. Relata que vai quase que semanalmente para Goiânia buscar o apoio da mãe e fala diariamente com a mesma por telefone. "Minha mãe... é meu suporte", afirma ela no completamento.

Dentro de uma perspectiva histórica, Kitzinger (1978) ajuda-nos a pensar a situação da rede de apoio restrita com que contou Vanuza e com que contam, invariavelmente, as mães da modernidade. Até alguns anos atrás, quando as famílias eram mais numerosas, era comum a filha mais velha cuidar do irmão mais novo. Desta forma, quando tinham seus próprios filhos, sentiam-se mais capacitadas e seguras em assumi-los. Hoje em dia, é mais difícil passar por esta experiência, já que todos na família saem para trabalhar e pouco se ajudam. Vanuza parece que não teve a oportunidade de treinar o papel materno antes e ficou ainda mais dependente de sua mãe após o nascimento da filha. 
Outro tema recorrente nas falas de Vanuza que aparece nas sessões em grupo, no completamento de frases, e na Escala de Edimburgo, está relacionado à privação de sono. Vejamos algumas de suas respostas a esse respeito: "Eu tenho me sentido tão infeliz que eu tenho tido dificuldade de dormir: sim, algumas vezes", "Estou muito cansada, não consigo dormir, porque acordo várias vezes durante a noite para amamentar a Carol. Ela mama 5 minutinhos e volta a dormir, em uma hora acorda novamente, e quer mamar".

Dix (1992) diz que a privação do sono causa irritabilidade, pensamentos paranóicos, alucinações visuais e explosões de cólera, coisas conhecidas por muitas de nós que temos que levantar toda noite com um ou mais filhos. As interrupções dos ciclos de sono, complementa a autora, afetam a nossa capacidade para reter informação, relaxar os nervos e processar as emoções. Por isto, lhe parece estranho que não exista um estudo sério sobre os efeitos da privação do sono nas mães, sobre as interrupções dos ciclos do que constituem um elemento intrínseco do período pós-parto. Interessante notar que apesar dos prejuízos que esta privação de sono lhe traz, Vanuza resiste em dividir tarefas com seu esposo e com a sua empregada, confiando a filha apenas a sua mãe que está há quilômetros de distância.

Esta resistência aponta para relação entre culpa materna e estilo de maternidade veiculado ao longo das gerações, ou seja: o homem adquire o privilégio do exercício da paternidade voluntária, enquanto a mulher se submete à maternidade obrigatória. Não existem sanções sociais para o homem quando se nega a ter filhos ou a cuidar bem deles, para mulher, entretanto, não é bem assim que funciona. No entanto, Vanuza parece se submeter a esta regra social a um alto custo emocional, indicando que faz questão de ser a supermulher. Inclusive é extremamente difícil para ela reconhecer-se deprimida. Várias vezes ela afirmou que estaria passando apenas por uma fase estressante e que seu problema resume-se à dificuldade de dormir um sono satisfatório.

Paradoxalmente, durante várias sessões Vanuza reclamava da sobrecarga da dupla jornada de trabalho e da obrigatoriedade de duplo êxito. Seu discurso dava voltas na desesperança e sensação de que com ela tudo era mais difícil, como cuidar da filha, da casa, do marido e ter sucesso profissional: No completamento ela escreve: "Minhas aspirações: ser boa mãe e uma boa profissional; Meu principal problema... é dividir meu tempo, minhas tarefas; Me esforço... para ser uma boa mãe; É difícil... ter que satisfazer o esposo”. Mais uma vez a supermulher entra em cena! Esta configuração subjetiva de Vanuza nos faz lembrar de Forna (1999) quando ela diz que, o que a princípio podia parecer ascensão da mulher para um status superior com a sua entrada no mercado de trabalho, mostra, na verdade, a onerosa sobrecarga do duplo papel, congregando tanto o papel de provedora como o de responsável pelos cuidados domésticos, além de ser também a mantenedora dos vínculos afetivos familiares.

Nesse sentido, Forna (1999) nos diz que é importante ressaltar que as mulheres têm interiorizado a ótica domi- nante quanto aos papéis parentais. Historicamente, a concepção da mulher como um ser inferior ao homem pode ter contribuído para a difusão e manutenção da ideologia do instinto materno e do sacrifício entre as mulheres. Talvez as mulheres tenham assimilado tão prontamente este papel porque, aparentemente, lhes conferia um espaço, o único, no qual eram consideradas superiores aos homens.

Soma-se aos fatores anteriormente citados, o fato da gravidez de Vanuza ter vindo após alguns anos de tratamento de reprodução assistida e de três episódios de abortos espontâneos. A evolução da gravidez contou com uma ameaça de perda do feto e de perigo para vida de Vanuza. Entendemos que esses eventos pessoais, subjetivos, de valor potencialmente traumático tiveram grande impacto na vida de Vanuza. Em alguns relatos ela apresenta um pequeno recorte do quão doloroso foi para ela sua história de tentativas de engravidar e o próprio período gestacional.

A partir da técnica de colagem, Vanuza relata que "Ser mãe é pisar em uma casquinha de ovo, e os dois podem quebrar" Esse discurso nos remete ao sentimento de fragilidade em que Vanuza se encontrava. É a fragilidade de uma mãe diante da fragilidade de um filho, é o desespero de quem se vê responsável por alguém no momento em que se sente terrivelmente fragilizada. A casquinha de ovo sugere a fragilidade de um útero que facilmente se quebra, o que aponta para a situação dos seus abortos recorrentes. Simbolicamente, Vanuza expressa o quanto ela se percebe frágil, uma vez que não conseguiu sustentar e manter até o final suas gestações anteriores. É um sentimento de fragilidade com relação ao seu próprio corpo. Um corpo sentido como fraco, um corpo sentido como doente. Daí porque a gravidez ficou longe de ser um momento prazeroso, de plenitude. Na verdade, a gravidez foi um período marcado por incertezas, dúvidas, ansiedade e medo da perda, sentimentos incompatíveis com ideal de maternidade interiorizado por ela. Sugerimos, portanto, que esse longo período de tratamento, os abortos recorrentes, bem como o risco de vida durante a gravidez são co-fatores que aliados aos fatores sociais anteriormente citados, contribuíram, também, para o aparecimento da depressão pós-parto em Vanuza.

Um outro desdobramento da infertilidade com repercussão na vida sexual de Vanuza pode ser clarificado pelo pensamento de Maldonado (2002). Segundo essa autora, desde muitos séculos, a fertilidade é tida como bênção divina, ao passo que a infertilidade é tida como castigo. Partindo dessa concepção, percebemos que Vanuza embarcou na maternidade com uma culpa antecipada devido ao fato da infertilidade representar um castigo, e tem vivenciado sua função de mãe com grande ansiedade, acreditando que cumpriria com todos os mandamentos da lei materna, acreditando que iria fazer tudo certo, decidida a não errar.

Trindade (1993) nos lembra que o modelo tradicional da maternidade apresenta a mulher como uma figura feminina responsável pela manutenção do vínculo familiar e que esta tarefa deve ter prioridade sobre suas necessidades pessoais, visto que é através da maternidade que se 
concretizará sua identidade como mulher. A maternagem é vista, então, como o ideal feminino mais nobre e dignificante, o qual Vanuza quer alcançar a todo custo.

É válido, portanto, lembrar que gestar e criar filhos são dimensões humanas que têm se transformado historicamente, mas que apesar disso a representação social acerca da maternidade ainda busca corresponder a um ideal de mãe infalível em tempo integral. Essa obrigatoriedade em obter satisfação absoluta exclusivamente a partir da maternidade pode ter desdobramentos prejudiciais, principalmente, em uma sociedade em que a mulher normalmente trabalha fora, também é responsável pelo orçamento familiar e cultiva interesses diversos. Estes elementos aparecem muito bem representados no caso de Vanuza.

\section{Considerações Finais}

A produção de uma conclusão é comum a todos os escritos, mas no nosso caso, não temos a pretensão de colocar um marco definitivo no trânsito sobre o problema da depressão pós-parto. . Ao contrário, revendo o que foi escrito, é possível notar que há ainda várias lacunas de pontos que devem ser mais explorados e nosso trabalho pretende ser apenas mais uma contribuição ao estudo desta problemática.

O estudo de caso nos permitiu levantar indicadores que podem ter contribuído para o aparecimento da depressão pós-parto em Vanuza. Quais sejam:

Entendemos que a impossibilidade de corresponder a altos ideais ligados a maternidade (a mãe perfeita, o filho ideal, a satisfação absoluta com o papel de mãe, etc) acabou por suscitar em Vanuza sentimentos de desapontamento, de vergonha, de desilusão, de fracasso, de fragilidade em relação a ela mesma.

Vanuza não pôde contar com a rede social de apoio tradicional, principalmente com aquela pessoa em quem ela realmente confiava (a mãe), representante da rede social comum em gerações anteriores. Em contrapartida, ela sentiu-se cada vez mais pressionada com relação ao fato de ser boa mãe o que incluía, diferentemente do que acontecia com mulheres das gerações anteriores, responsabilidade pelo desenvolvimento das aptidões físicas e emocionais da filha.

Para Vanuza, a impossibilidade de uma discussão plena acerca das ambivalências comuns na maternidade acabou por suscitar conflitos e sentimentos de inadequação que favoreceram o surgimento da depressão pós-parto. Vanuza sentiu-se marginalizada, uma vez que não se adequava ao estereotipo de instinto maternal, segundo o qual a maternidade ocupa o lugar de complemento de um ser faltante. Dessa forma, pensamos que o humor deprimido em Vanuza expressa o sofrimento pela perda de imagens idealizadas com relação ao bebê, a si mesma como mãe e ao tipo de vida que se estabeleceu com a presença do filho.

Espera-se que as mães sejam sempre ternas, acolhedoras, férteis e disponíveis, em contrapartida, elas não deverão demonstrar sentimentos de tristeza, afinal, tudo isso está ligado ao milagre da vida que presume um instinto materno, uma predisposição inata para o sacrifício. Oporse a essa visão romanceada da maternidade é, para algumas mulheres, opor-se à feminilidade.

Não é por acaso que ser mãe na modernidade suscita sentimentos de culpa e frustração e conflitos de identidade, afinal as mães estão habituadas a uma cultura que proíbe a discussão plena da ambivalência materna, da coexistência de sentimentos ambivalentes natural em todas as mães. O natural passa a ser o sacrifício e o amor irrestrito.

E o que dizer das mães que tentam associar essa "maternidade cinco estrelas" a uma carreira profissional bem sucedida? O estudo de caso nos faz concluir que essa é uma tarefa muito ambivalente. A maneira de exercer a maternidade tem se tor nado cada dia mais idealizada, e em contrapartida, aumentam as atribuições na vida das mulheres no que se refere à assunção de novos papéis sociais exigidos pela cultura moderna.

No grupo, trabalhamos a idéia de que o amor materno não é puro instinto, mas é um sentimento construído paulatinamente, na vivência diária da maternagem e por isso está sujeito a imperfeições, oscilações e modificações, o que trouxe para as mães, de forma geral, grande alívio. A livre expressão dos sentimentos e sua maior exploração são encorajadas e estimuladas através do clima de permissividade que se estrutura no grupo e da técnica de reflexão de sentimentos. É nesse aspecto que mais se aprofunda o valor terapêutico do grupo, pois permite manejar sentimentos básicos em relação à maternidade, tais como níveis de insegurança, sentimentos de inferioridade e inadequação e expectativas referentes ao bebê e a si própria como mãe.

É nesse sentido que Maldonado (2002) desenvolve a hipótese de que o grupo de discussão permite compartilhar as vivências basicamente comuns em relação à maternidade e às modificações conseqüentes. A ênfase, diz Maldonado (2002), deve ser dada ao manejo da ambivalência afetiva em suas várias manifestações, com a finalidade principal de aliviar os sentimentos de culpa e a crença na própria maldade interna e na própria capacidade de destruição.

Concordamos com Maldonado (2002), que é preciso evitar encorajar apenas a expressão dos sentimentos positivos, o que criaria uma imagem muito incompleta da totalidade das vivências maternas, ao contrário, deve-se estimular também a expressão dos sentimentos negativos, de hostilidade e rejeição, das ansiedades, temores e dúvidas a fim de que, através da elaboração, faça-se emergir mais plenamente os sentimentos de amor e ternura e, sobretudo, ajude a entender as dimensões polivalentes que compõem cada relação humana. Acreditamos que foi essa elaboração que foi possível tornar a maternagem menos angustiante para Vanuza e os sentimentos depressivos menos presentes, no final do processo terapêutico. 


\section{Referências}

Badinter, E. (1985). Um amor conquistado: O mito do amor materno. Rio de Janeiro, RJ: Nova Fronteira.

Brito, A X., \& Leonardos, A. C. (2001). A identidade das pesquisas qualitativas: Construção de um quadro analítico. Cadernos de Pesquisa, 113, 1-19.

Diniz, G. S. R. (1999). Condição feminina - Fator de risco para a saúde mental? In M. G. T. Paz \& A. Tamayo (Eds.), Escola, saúde e trabalho: Estudos psicológicos (pp. 179-198). Brasília, DF: Editora da Universidade de Brasília.

Dix, C. (1992). Depresión posparto. Como superar el estrés y la depresión que suceden al parto. Madri, España: Apóstrofe.

Falcke, D., \& Wagner, A. (2000). Mães e madrastas: Mitos sociais e auto-conceito. Estudos de Psicologia, 5(2), 42 1-441.

Forna, A. (1999). Mãe de todos os mitos: Como a sociedade modela e reprime as mães. Rio de Janeiro, RJ: Ediouro

González Rey, F. (1997). Epistemología cualitativa y subjetividad. São Paulo, SP: EDUC.

González Rey, F. (1999). La investigación cualitativa en Psicología: Rumbos y desafios. São Paulo, SP: EDUC.

González Rey, F. (2001). La categoría de sentido subjetivo y su significación en la construcción del pensamiento psicológico. Contrapontos, 1(2), 13-28.

González Rey, F. (2002). Sujeito e subjetividade. São Paulo, SP: Thomson / Pioneira.

Kitzinger, S. (1978). Mães - Um estudo antropológico da maternidade. Lisboa, Portugal: Presença.

Maldonado, M. T. (2002). Psicologia da gravidez (16. ed.). São Paulo, SP: Saraiva.

Maldonado, M. T., Dickstein, J., \& Nahoum, J. C. (2000). Nós estamos grávidos. São Paulo, SP: Saraiva.

Parker, R. (1997) A mãe dividida: A experiência da ambivalência na maternidade. Rio de Janeiro, RJ: Rosa dos Tempos.

Santos, M. F. S. dos (1995). Depressão no pós-parto: Validação da escala de Edimburgo em puérperas brasilenses. Dissertação de Mestrado não-publicada, Curso de Pós-Graduação em Psicologia, Universidade de Brasília, DF.

Santos, M. F. S. dos, Martins, F. C., \& Pasquali, L. (1999). Escalas de auto-avaliação de depressão pós-parto: Um estudo no Brasil [Ver são eletrônica]. Revista de Psiquiatria Clínica, 26(2). Retirado em http://www.hcnet.usp.br/ipq/revista/r262/ $\operatorname{artigo(90)\cdot htm}$

Serrurier, C. (1993). Elogio às mães más. São Paulo, SP: Summus.

Trindade, Z. A. (1993). As representações sociais e o cotidiano: A questão da maternidade e da paternidade. Psicologia: Teoria e Pesquisa, 9(3), 535 - 546. 